\title{
Financial Fragility and Interbank Structure
}

\author{
Yalan Feng ${ }^{1}$ \\ ${ }^{1}$ College of Business and Economics, California State University Los Angeles
}

Correspondence: Yalan Feng, Department of Finance and Law, CBE, Simpson Tower, California State University Los Angeles, Los Angeles, CA 90032, USA. Tel: 1-323-343-2863. E-mail: yfeng10@ calstatela.edu

Received: February 14, 2018

Accepted: June 14, 2018

Online Published: June 25, 2018

doi:10.5430/afr.v7n3p138

URL: https://doi.org/10.5430/afr.v7n3p138

\begin{abstract}
This paper follows Allen and Gale (2000) to model financial contagion as an equilibrium phenomenon. I assume a two-country economy where banks in each country hold interregional claims on other banks to provide insurance against liquidity preference shocks. The results replicate Allen-Gale model. To further test the relative robustness of different market structures I test the implication of moral hazard as in Brusco and Castiglionesi (2007). I find that under certain situation, complete and incomplete structures are equally fragile.
\end{abstract}

Keywords: interbank structure, financial fragility, financial contagion

\section{Introduction}

Following the subprime mortgage crisis originated in the US, the country's whole financial sector had been in crisis. Moreover, the crisis spread to countries that did not appear to have common economic fundamentals as the US. Banks provide liquidity in the financial markets while being exposed to the risk of bank runs (Diamond and Dybvig, 1983). When bank runs occur, they spread across institutions and countries (See Schmidt, Timmermann, and Wermers (2015) and Covitz, Liang, and Suarez (2013)). One of the leading explanations is the interbank connections studies by Allen and Gale (2000) and Freixas, Parigi, and Rochet (2000). These studies find that the architecture of the system of cross-holding is influential in the system fragility. More specifically, a complete system where each bank borrows from and lends to all other banks is less fragile than an incomplete system where each bank borrows from one of the other banks. The crisis addressed by Allen and Gale is liquidity crisis. Bank deposit contracts allow depositors to withdraw the previously agreed amount on demand. Banks use a fraction of these deposits to finance illiquid and risky investments. There is a possibility that banks cannot meet the withdrawal demand of depositors and will result in a liquidity crisis. In a complete market structure, banks hold deposits among each other so any banks does not depend on any single bank too strongly. When damage occurs, it spreads out evenly and is not big enough to fail other regions. On the other hand, Brusco and Castiglionesi (2007) study the propagation of financial crises among regions in which banks are protected by limited liability and may take excessive risk. Their conclusion is the opposite: a more connected interbank deposit market increases the number of regions affected.

This paper studies financial fragility in the banking sector due to interbank lending relationships from a theoretical perspective. Following Allen and Gale (2000) and Goldstein and Pauzner (2005), I assume a two-country economy where banks in each country hold interregional claims on other banks to provide insurance against liquidity preference shocks. I also apply moral hazard to the model to test for robustness of different market structures. The question of interest is which market structure, the complete structure or the incomplete structure is more vulnerable to contagion risk.

The organization of this paper is as follows. Section 2 presents literature review on bank runs, bank panics, and financial fragility. Section 3 provides a description of the model and section 4 presents the analysis. Conclusions and further possible studies are given in section 5 .

\section{Literature Review}

During a financial crisis, particularly in the late 19th century and early 20th century, there have been massive withdrawals of bank deposits. It then goes further beyond the financial system and affects the real economy. Bank run is a major type of crisis. Diamond and Dybvig (1983) provide a simple model of bank runs that is inherently tied to the basic role of banks. Banks create liquid claims on illiquid assets using demand deposit contracts. These 
contracts enable investors with early liquidity needs (impatient depositors) to participate in long-term investments and provide risk sharing. The main insight is that with such contracts banks can replicate the first-best allocation and thus overcome the fact that depositor types (impatient and patient) are not known ex ante. This model leads to two Nash equilibriums: a good equilibrium in which only impatient depositors demand early withdrawal and the first-best allocation is achieved and a bad equilibrium in which all agents demand early withdrawal and bank run occurs. In this case, bank runs are panic-based rather than fundamental-based. They occur because of the self-fulfilling beliefs of depositors that other depositors are going to run. The shortcoming of the model is that it does not tell how to determine which equilibrium is more likely to occur. If we take into consideration the probability of runs, then the optimal contracts may not be optimal.

Two main regulatory responses to fragility are suspension of convertibility and deposit insurance. If the proportion of impatient consumers is known, the bank can announce that after this proportion of depositor withdrawal in period 1, no one else gets money in this period. Patient consumers, therefore, know that the bank will be able to satisfy its engagements at date 2 , and thus have no interest in withdrawing at date 1 . Then the good equilibrium becomes the unique equilibrium. The problem is that in reality the number of impatient agents is not known. Hence suspension of convertibility may severely hurt those impatient agents who cannot get early withdrawal. In deposit insurance case, even if the bank is not able to pay, depositors receive the full value of their deposits from insurance system. We can assume that the government obtains this amount by taxing depositors. This approach also leads to the good equilibrium. Patient agents know that the withdrawal by others is not going to harm their long-term return and thus do not choose to run. The problem is that it might cause moral hazard problem when banks intend to make too risky investments.

Since the runs in Diamond-Dybvig model are not information-based, some referred to such runs as "sunspots". Chari and Jagannathan (1988) try to explain runs on the basis of an informational story. Agents run when they see others run because they know others may have information about the fundamentals. That is, in period 1, impatient agents and negatively informed agents withdraw whereas positively informed agents keep investing. The uninformed agents observe the proportion of withdrawing agents and make a decision to withdraw or not. The key is that uninformed agents cannot distinguish withdrawal by impatient agents and negatively informed agents. The equilibrium outcome is that runs are correlated with bad fundamentals, but there are unjustified runs in equilibrium in which uninformed agents interpret the long line in front of the bank as due to many negatively informed agents.

Due to the global-game literature by Carlsson and van Damme (1993), there have been more theoretical developments on panic-based stories. Morris and Shin (1998) model currency attack by speculators by introducing imperfect information. Speculators observe information about fundamentals with noise. They choose whether to attack or not based on the observed imperfect signals. Since their signals are with noise, they also take into account other speculators actions at other signals. The equilibrium result shows that in the extreme cases of fundamentals, fundamentals determine speculators actions, and in the intermediate region, attacks are basically driven by bad expectations, i.e. speculators believe others will do.

Following Morris and Shin (1998), Goldstein and Pauzner (2005) use global-games approach to address the fundamental issues in the Diamond-Dybvig model. In their model, fundamentals determine which equilibrium occurs. This enables the calculation of ex ante probability of panic-based runs. Chen, Goldstein, and Jiang (2010) provide empirical evidence of the presence of strategic complementarities among investor using mutual fund outflows. Because bank runs could also occur when banks fundamentals are weak even with deposit insurance, Allen, Carletti, Goldstein, and Leonello (2015) build on Goldstein and Pauzner (2005) to add a government to the model and find that government's guarantees can increase the probability of crisis.

Interbank connection is one of the leading explanations of why financial crises spread across countries. Bhattacharya and Gale (1987) assume there are a large number of banks confronted with i.i.d. liquidity shocks so liquidity shocks of all banks are completely diversifiable. the proportion of banks with few early withdrawals is known. At date 1, banks with excess liquidity and banks with liquidity needs lend to and borrow from each other so that supply and demand of liquidity are matched. At date 2, banks face the opposite liquidity shock of their first period, thus previous borrowers repay the loan to the previous lenders. Allen and Gale (2000) study the relationship between the possibility of contagion and the completeness of the structure of interregional claims. They assume there are four regions, A, B, C, and D, with imperfectly correlated liquidity preference shocks. Banks hold claims on other banks to provide insurance against the shocks. If there is no aggregate uncertainty, the first-best allocation can be achieved. However, there is inherent fragility where a small liquidity shock in one region can spread by contagion throughout the economy, and it is more fragile when they system structure is incomplete. 
Brusco and Castiglionesi (2007) in their paper about moral hazard and financial contagion also analyze which interbank deposit market structure is more resistant to contagion. They get the opposite result that a more connected interbank deposit market increases the number of regions affected, although in the connected case the amount of financial distress experienced by the banks affected by the contagion will typically be lower.

Goldstein and Pauzner (2004) look at two countries that have independent fundamentals but share the same group of investors. Each country might face a self-fulfilling crisis: agents withdrawing their investments fearing that others will. Each agent observes a noisy signal on the fundamentals of both countries. Under a sequential framework in which the events in country 2 take place after the aggregate outcomes in country 1 are realized and become known to all agents, they show that there is a unique threshold in country 2 below which agents run.

The analysis of the specific literature has shown how authors disagree on the relative robustness of complete and incomplete structures. Furthermore, very few empirical studies give evidence on the relation between the structure of the interbank deposit market and the propagation of contagion.

\section{Model}

The framework is based on Diamond and Dybvig (1983) and Allen and Gale (1998, 2000). Consider a one-good, three-dates $(t=0,1,2)$ economy in which a continuum of agents, each endowed with one unit of good at date $t=0$. These agents are ex ante identical, with the usual Diamond-Dybvig preferences, subject to i.i.d liquidity shocks at $\mathrm{t}=1$. With probability $\pi_{i}\left(\pi_{1}+\pi_{2}=1\right)$ one prefers to consume at date $\mathrm{t}=\mathrm{i}$. The utility of agent type $\mathrm{i}=1$ (impatient consumers) is $u\left(c_{1}\right)$ and the utility of agent type $\mathrm{i}=2$ (patient consumers) is $u\left(c_{2}\right)$. Ex ante, all agents have the same utility $U=\pi_{1} u\left(c_{1}\right)+\pi_{2} u\left(c_{2}\right)$.

There is a storage technology that allows transfer of the good without cost from one date to the next. The assets invested through storage technology are referred to as short assets. There is also a long-term illiquid technology where one unit invested at $\mathrm{t}=0$ gives a return $\mathrm{R}>1$ at $\mathrm{t}=2$. If they are liquidated prematurely at $\mathrm{t}=1$, they produce $0<\mathrm{r}<1$ units of good. Assets invested through long-term technology are referred to as long assets.

Different from Allen and Gale (2000), the economy is composed of two countries (or regions or sectors) that have different fundamentals. Each country has two regions (or banks if we assume each region has one representative bank). Without loss of generality, country 1 has regions A and B and country 2 has regions C and D. The return for each region depends both on the fundamentals of the country $\left(\theta_{i}\right)$ and idiosyncratic attributes of the banks $\left(\delta_{i}\right)$. Patient agents at $\mathrm{t}=1$ make their decision to withdraw or not based on their observed signals of bank prospects $\theta_{i}+\delta_{i}$. The higher the sum of $\theta$ and $\delta$, the less likely the early withdrawal by patient agents.

\subsection{A Simple Model}

Let $\omega_{i}$ be the probability of being an early consumer in region i. Allen and Gale (2000) assume that there are two values of $\omega_{i}$, where $0<\omega_{L}<\omega_{H}<1$. The realization depends on the state of nature. There are two equally likely states $S_{1}$ and $S_{2}$. Allen and Gale (2000, Table 1) gives the realization of the state-dependent liquidity preference shocks in each region.

Table 1. Regional Liquidity Shocks

\begin{tabular}{ccccc}
\hline & $\mathbf{A}$ & $\mathbf{B}$ & $\mathbf{C}$ & $\mathbf{D}$ \\
\hline $\mathbf{S}_{\mathbf{1}}$ & $\omega_{H}$ & $\omega_{L}$ & $\omega_{H}$ & $\omega_{L}$ \\
$\mathbf{S}_{\mathbf{2}}$ & $\omega_{L}$ & $\omega_{H}$ & $\omega_{L}$ & $\omega_{H}$ \\
\hline
\end{tabular}

Let $\gamma$ denote the average fraction of early consumers, $\gamma=\left(\omega_{L}+\omega_{H}\right) / 2$. For simplicity, let's assume that country 1 and country 2 have negatively related fundamental shocks, and that within each country, the two regions have negatively related individual shocks. Further assume that there are only three possible values of

$\omega_{i}: \omega_{i}=\omega_{H}$ if and only if the bank experiences both high individual liquidity shock and high fundamental shock, $\omega_{i}=\omega_{L}$ if and only if the bank experiences both low individual shock and low fundamental shock. Otherwise, $\omega_{i}=\gamma=\left(\omega_{L}+\omega_{H}\right) / 2$. 
Table 2. Modified Regional Liquidity Shocks

\begin{tabular}{ccccc}
\hline & $\mathbf{A}$ & $\mathbf{B}$ & $\mathbf{C}$ & $\mathbf{D}$ \\
\hline $\mathbf{S}_{\mathbf{1}}$ & $\omega_{H}$ & $\gamma$ & $\omega_{L}$ & $\gamma$ \\
$\mathbf{S}_{\mathbf{2}}$ & $\omega_{H}$ & $\gamma$ & $\gamma$ & $\omega_{L}$ \\
$\mathbf{S}_{\mathbf{3}}$ & $\gamma$ & $\omega_{H}$ & $\omega_{L}$ & $\gamma$ \\
$\mathbf{S}_{\mathbf{4}}$ & $\gamma$ & $\omega_{H}$ & $\gamma$ & $\omega_{L}$ \\
$\mathbf{S}_{\mathbf{5}}$ & $\omega_{L}$ & $\gamma$ & $\omega_{H}$ & $\gamma$ \\
$\mathbf{S}_{\mathbf{6}}$ & $\omega_{L}$ & $\gamma$ & $\gamma$ & $\omega_{H}$ \\
$\mathbf{S}_{7}$ & $\gamma$ & $\omega_{L}$ & $\omega_{H}$ & $\gamma$ \\
$\mathbf{S}_{\mathbf{8}}$ & $\gamma$ & $\omega_{L}$ & $\gamma$ & $\omega_{H}$ \\
\hline
\end{tabular}

There are eight equally likely states, $S_{1}$ through $S_{8}$. The corresponding realizations of the liquidity shocks are given in table 2. The aggregate demand for liquidity is the same in each state: one region has a high liquidity preference, two regions have an average liquidity preference, and one region has a low liquidity preference. When the state of nature is revealed at $\mathrm{t}=1$, each consumer learns his type.

\section{Interbank Structure Analysis}

Follow Allen and Gale (2000), I first characterize the optimal allocation of risk. At $\mathrm{t}=0$, social planner chooses a portfolio $(x, y) \geq 0$ subject to the feasibility constraint

$$
x+y \leq 1
$$

where $\mathrm{x}$ and $\mathrm{y}$ are the per capita amount invested in the long and short assets.

The feasibility constraints are

$$
\gamma c_{1} \leq y
$$

for early consumption with short assets and

$$
(1-\gamma) c_{2} \leq R x
$$

for late consumption with long assets. The planner's problem is

$$
\max _{\{c 1, c 2, x, y\}} \gamma u\left(c_{1}\right)+(1-\gamma) u\left(c_{2}\right)
$$

under constraints (1) (2) (3). The unique solution to planner's problem is the first-best allocation.

\subsection{Decentralization}

The first-best allocation can also be achieved within the competitive banking sector. Let's assume each consumer deposits his endowment of one unit in the representative bank in his region. The bank invests the deposit in a portfolio $(x, y) \geq 0$ and offers a deposit contract $\left(\mathrm{c}_{1}, \mathrm{c}_{2}\right)$ that allows the consumer to withdraw either $\mathrm{c}_{1}$ units at $\mathrm{t}=1$ or $\mathrm{c}_{2}$ units at $\mathrm{t}=2$.

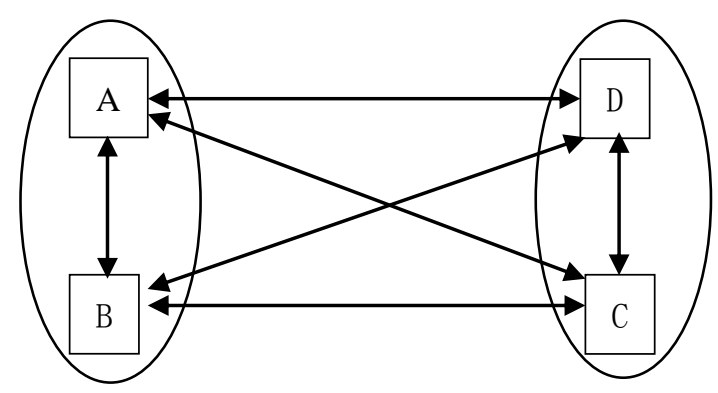

Figure 1. Complete market structure

In a complete market structure illustrated in figure 1, each bank exchanges deposits with all other banks at $t=0$. We assume that each bank holds $\mathrm{z}$ units of deposits in every other bank. The budget constraints of banks in a region with a high, average, and low demand for liquidity are discussed one by one as follows. 
For a bank in a region with a high demand for liquidity, it must pay $c_{1}$ to the $\omega_{H}$ fraction of early consumers. To do so, it uses y units of the short assets and claims $3 z$ deposits in other regions. Thus the budget constraint is:

$$
\omega_{H} c_{1}=y+3 z c_{1}
$$

Banks in a region with an average demand for liquidity can use y units to pay early consumers. But since z unit of deposits has been claimed by the bank with high liquidity demand, it must also claim its deposit in the bank with low liquidity demand to make ends meet. Thus the budget constraint is:

$$
(\gamma+z) c_{1}=y+z c_{1}
$$

Finally, a bank with a low liquidity demand pay $c_{1}$ to a fraction of $\omega_{L}$ of depositors and redeem $3 z$ deposits from the banks in other regions. The budget constraint is:

$$
\left(\omega_{L}+3 z\right) c_{1}=y
$$

From equation (5), we have $\gamma c_{1}=y$, which is just the planner's constraint. We can also solve for $\mathrm{z}$ from (4) to get $z=\left(\omega_{H}-\gamma\right) / 3$.

At $\mathrm{t}=2$, all banks get the return from long-term assets and redeem and claim the deposits from other banks. The budget constraints for the three types of banks are

$$
\begin{gathered}
\left(1-\omega_{H}+3 z\right) c_{2}=R x \\
(1-\gamma+2 z) c_{2}=R x+2 z c_{2} \\
\left(1-\omega_{L}\right) c_{2}=R x+3 z c_{2}
\end{gathered}
$$

From equation (8), we have $(1-\gamma) c_{2}=R x$, which is just the planner's constraint. Equations (7) and (9) can also be simplified to this relationship. Thus, banks in all regions can satisfy their budget constraints and provide first-best allocation.

\subsection{Incomplete Market Structure}

In the incomplete market structure in Allen-Gale model banks do not mutually hold deposits in one another. Without loss of generality, in our model, we assume region A experiences high liquidity demand. There are 4 scenarios illustrated in figure 2 (Note 1). The arrow direction shows a deposit relationship where $A \rightarrow B$ means $A$ holds deposits in B. 


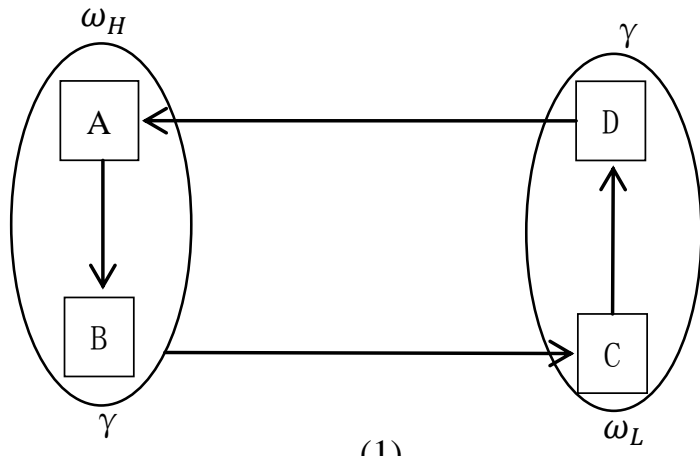

(1)

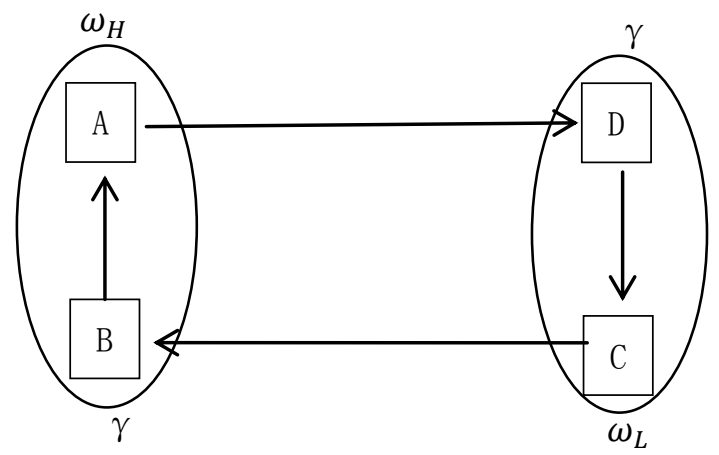

(3)

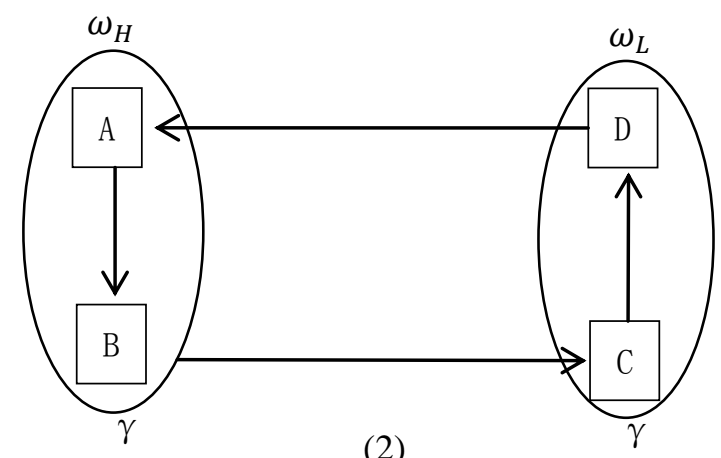

(2)

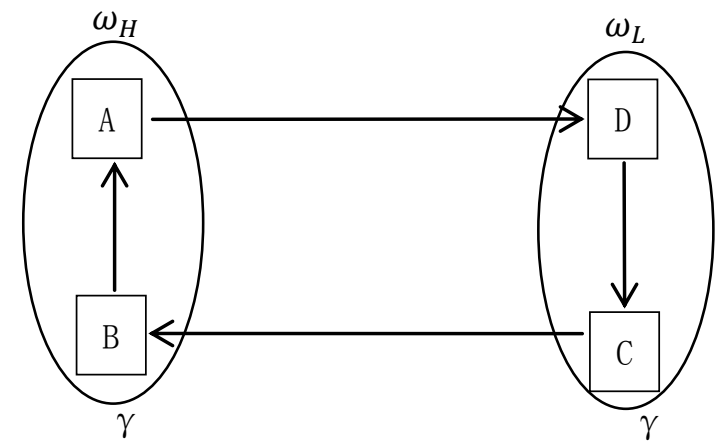

(4)

Figure 2. Modified Incomplete Market Structure

Notice that (1) and (3) describe the same situation where A both holds a deposit at and receives a deposit from banks experiencing the same level $(\gamma)$ of liquidity shock, the following discussion will just focus on cases (1) (2) and (4). Following the same arguments in section 4.1, the budget constraints are summarized in table 3.

Table 3. Budget Constraints under incomplete market structure

\begin{tabular}{lccc}
\hline $\mathrm{t}=1$ & $(1)$ & $(2)$ & $(4)$ \\
\hline $\mathrm{A}$ & $\omega_{H} c_{1}=y+z c_{1}$ & $\omega_{H} c_{1}=y+z c_{1}$ & $\omega_{H} c_{1}=y+z c_{1}$ \\
$\mathrm{~B}$ & $(\gamma+z) c_{1}=y+z c_{1}$ & $(\gamma+z) c_{1}=y+z c_{1}$ & $\gamma c_{1}=y$ \\
$\mathrm{C}$ & $\left(\omega_{L}+z\right) c_{1}=y$ & $(\gamma+z) c_{1}=y+z c_{1}$ & $\gamma c_{1}=y$ \\
$\mathrm{D}$ & $\gamma c_{1}=y$ & $\left(\omega_{L}+z\right) c_{1}=y$ & $\left(\omega_{L}+z\right) c_{1}=y$ \\
\hline $\mathrm{t}=2$ & $(1)$ & $(2)$ & $(4)$ \\
\hline $\mathrm{A}$ & $\left(1-\omega_{H}+z\right) c_{2}=R x$ & $\left(1-\omega_{H}+z\right) c_{2}=R x$ & $\left(1-\omega_{H}+z\right) c_{2}=R x$ \\
$\mathrm{~B}$ & $(1-\gamma) c_{2}=R x$ & $(1-\gamma) c_{2}=R x$ & $(1-\gamma+z) c_{2}=R x+z c_{2}$ \\
$\mathrm{C}$ & $\left(1-\omega_{L}\right) c_{2}=R x+z c_{2}$ & $(1-\gamma) c_{2}=R x$ & $(1-\gamma+z) c_{2}=R x+z c_{2}$ \\
$\mathrm{D}$ & $(1-\gamma+z) c_{2}=R x+z c_{2}$ & $\left(1-\omega_{L}\right) c_{2}=R x+z c_{2}$ & $\left(1-\omega_{L}\right) c_{2}=R x+z c_{2}$
\end{tabular}

At $\mathrm{t}=1$, the budget constraints simplify to $\gamma c_{1}=y$, and we also obtain $z=\omega_{H}-\gamma$. At $\mathrm{t}=2$, the budget constraints simplify to $(1-\gamma) c_{2}=R x$.

Therefore, we conclude that incomplete market structure can also satisfy budget constraints by switching deposits through the interbank market. Follow Allen-Gale's approach, I can get the same conclusion as in their proposition 2 that given a zero probability state $\bar{S}$ (The demand for deposits from early consumers is $\gamma+\varepsilon$ in $\mathrm{A}$, and $\gamma$ in $\mathrm{B}$, $\mathrm{C}$, and D), all banks in the incomplete structure system must go bankrupt at date $\mathrm{t}=1$ in state $\bar{S}$ if the shock in A exceeds A's buffer and the spillover effect to region D (in cases (1) and (2)) or regions B (in cases (3) and (4)) exceed the region's buffer. And because the financial interdependence on A is smaller in the complete structure, such structure is 
more robust.

\subsection{Moral Hazard and Contagion}

Brusco and Castiglionesi (2007) study the fragility of interbank market from a different perspective. Besides short assets and long assets, banks have the incentive to invest in gambling asset whose payoff is larger than the long asset if succeeded even though its expected payoff is smaller. With interbank structure, banks may take the risk to gamble. If the gambling bank fails, then contagion occurs because an otherwise solvent bank is unable to retrieve its deposits from the failed bank. In this subsection, I apply the moral hazard assumption to our model.

Assume bank A invested in gambling assets and failed. In the complete market structure, since all the other banks have deposits in A and cannot retrieve the deposits, all banks are affected and fail. This is the same as in Brusco-Castiglionesi model.

For the incomplete cases:

In case (1), at $\mathrm{t}=1$, bank $\mathrm{A}$ withdraws its deposit in $\mathrm{B}$, and $\mathrm{B}$ withdraws from $\mathrm{C}$. Bank $\mathrm{C}$ leave its deposit in $\mathrm{D}$ and $\mathrm{D}$ leave its deposit in $\mathrm{A}$. At $\mathrm{t}=2$, bank $\mathrm{A}$ fails so that $\mathrm{D}$ cannot retrieve its deposit in $\mathrm{A}$ and fails, and $\mathrm{C}$ cannot retrieve its deposit in D and fails. Only B has no link with other banks, so B survives;

In case (2), at $\mathrm{t}=1$, bank $\mathrm{A}$ withdraws its deposit in $\mathrm{B}$, and $\mathrm{B}$ withdraws from $\mathrm{C}, \mathrm{C}$ withdraws from $\mathrm{D}$. D leave its deposit in A. At $\mathrm{t}=2$, bank $\mathrm{A}$ fails so that $\mathrm{D}$ cannot retrieve its deposit in $\mathrm{A}$ and fails. $\mathrm{B}$ and $\mathrm{C}$ have no link with other banks, so $\mathrm{B}$ and $\mathrm{C}$ survive. This is the same result as in Brusco-Castiglionesi model where 2 banks survive;

In case (3), at $\mathrm{t}=1$, Bank A withdraws its deposit in $\mathrm{D}$, and $\mathrm{D}$ withdraws from $\mathrm{C}$. Bank $\mathrm{C}$ leave its deposit in $\mathrm{B}$ and $\mathrm{B}$ leave its deposit in $\mathrm{A}$. At $\mathrm{t}=2$, bank $\mathrm{A}$ fails so that $\mathrm{B}$ cannot retrieve its deposit in $\mathrm{A}$ and fails, and $\mathrm{C}$ cannot retrieve its deposit in B and fails. Only D has no link with other banks, so D survives. This result is the same as in case (1);

In case (4), at $t=1$, bank A withdraws its deposit in D. D leave its deposit in C. B and C does not withdraw from others and no other bank withdraws from them. At $\mathrm{t}=2$, Bank A fails so that B cannot retrieve its deposit in A and fails. C cannot retrieve its deposit in B and fails, D cannot retrieve its deposit in C and fails. All banks fail.

Therefore, considering all four cases, in two of the cases only one bank survive, in one of the cases two banks survive and in the last case, all banks fail. In terms of the number of failing banks, the last case scenario is as fragile as in complete structure where all banks fail. However, the distress experienced by banks in incomplete structure is higher.

\section{Conclusion}

This paper studies financial fragility in the banking sector due to interbank lending relationships based on Allen and Gale (2000). With a more complex model of interbank structure which can be applied to international banking sector and financial crisis across countries, I replicate Allen-Gale results. I also test the implications of the model from a moral hazard perspective. The results show that the relative fragility of complete and incomplete structures depends on the specific lending relationships between banks. In one of the four cases, the incomplete and complete structures are equally fragile in terms of the number of failed banks. Future research may extend the model to stochastic liquidity shocks and wealth effect on agents where crisis in one country makes agents poorer and more likely to withdraw from the other country thus spread the crisis.

\section{References}

Allen, Franklin, \& Douglas Gale. (1998). Optimal Financial Crises. Journal of Finance, 53, 1245-1284. http://dx.doi.org/10.1111/0022-1082.

Allen, Franklin, \& Douglas Gale. (2000). Financial Contagion. Journal of Political Economy, 108, 1-33. https://doi.org/10.1086/262109

Allen, Franklin, Elena Carletti, Itay Goldstein, \& Agnese Leonello. (2015). Moral Hazard and Government Guarantees in the Banking Industry. Journal of Financial Regulation, 1, 30-50. https://doi.org/10.1093/jfr/fju003

Bhattacharya, Sudipto, \& Douglas M. Gale. (1987). Preference Shocks, Liquidity, and Central Bank Policy, in New approaches to monetary economics: Proceedings of the Second International Symposium in Economic Theory and Econometrics (Cambridge; New York and Melbourne: Cambridge University Press).

Brusco, Sandro, \& Fabio Castiglionesi. (2007). Liquidity Coinsurance, Moral Hazard, and Financial Contagion. Journal of Finance, 62, 2275-2302. http://dx.doi.org/10.1111/j.1540-6261.2007.01275.x 
Carlsson, Hans, \& Eric van Damme. (1993). Global Games and Equilibrium Selection. Econometrica. 61, 989-1018. https://doi.org/10.2307/2951491

Chari, V. V., \& Ravi Jagannathan. (1988). Banking Panics, Information, and Rational Expectations Equilibrium. Journal of Finance, 43, 749-761. http://dx.doi.org/10.1111/j.1540-6261.1988.tb04606.x

Chen, Qi., Itay Goldstein \& Wei Jiang. (2010). Payoff complementarities and financial fragility: Evidence from mutual fund outflows. Journal of Financial Economics, 97(2), 239-262. https://doi.org/10.1016/j.jfineco.2010.03.016

Covitz, D. , Nellie Liang, \& Gustavo A. Suarez. (2013). The Evolution of a Financial Crisis: Collapse of the Asset-Backed Commercial Paper Market. Journal of Finance, 68, 815-848. https://doi.org/10.1111/jofi.12023

Diamond, Douglas W., \& Philip H. Dybvig. (1983). Bank Runs, Deposit Insurance, and Liquidity. Journal of Political Economy, 91, 401-419. https://doi.org/10.1086/261155

Freixas, Xavier, Bruno M. Parigi, \& Jean-Charles Rochet. (2000). Systemic Risk, Interbank Relations, and Liquidity Provision by the Central Bank. Journal of Money, Credit, and Banking, 32, 611-638. https://doi.org/10.2307/2601198

Goldstein, Itay, \& Ady Pauzner. (2004). Contagion of Self-Fulfilling Financial Crises Due to Diversification of Investment Portfolios. Journal of Economic Theory, 119, 151-183. https://doi.org/10.1016/j.jet.2004.03.004

Goldstein, Itay, \& Ady Pauzner. (2005). Demand-Deposit Contracts and the Probability of Bank Runs. Journal of Finance, 60, 1293-1327. http://dx.doi.org/10.1111/j.1540-6261.2005.00762.x

Morris, Stephen, \& Hyun Song Shin. (1998). Unique Equilibrium in a Model of Self-Fulfilling Currency Attacks. American Economic Review, 88, 587-597. http://www.jstor.org/stable/116850

Schmidt, Lawrence, Allan Timmermann, \& Russ Wermers. (2016). Runs on Money Market Mutual Funds. American Economic Review, 106(9), 2625-57. https://doi.org/10.1257/aer.20140678

\section{Notes}

Note 1 . Since two of the regions experience the same average liquidity at $t=1$, the model could be simplified to three regions with two scenarios, as illustrated in figure 3. The "less-simplified" model (figure 2) is used in order to replicate the results in Allen-Gale model.
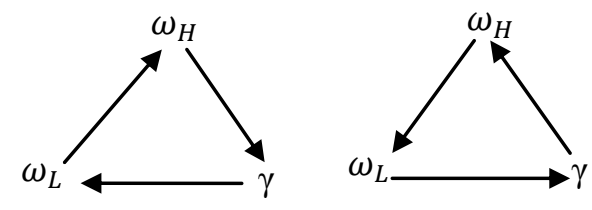

Figure 3. Simplified Incomplete Market Structure 